\title{
The relative roles of local climate adaptation and phylogeny in determining leaf-out timing of temperate tree species
}

\author{
Elsa Desnoues ${ }^{1 \dagger}$, Julie Ferreira de Carvalho ${ }^{1 \dagger}$, Constantin M. Zohner ${ }^{2,3}$ and Thomas W. Crowther ${ }^{1,3^{*}}$
}

\begin{abstract}
Background: Leaf out times of temperate forest trees are a prominent determinant of global carbon dynamics throughout the year. Abiotic cues of leaf emergence are well studied but investigation of the relative roles of shared evolutionary history (phylogeny) and local adaptation to climate in determining the species-level responses to these cues is needed to better apprehend the effect of global change on leaf emergence. We explored the relative importance of phylogeny and climate in determining the innate leaf out phenology across the temperate biome.

Methods: We used an extensive dataset of leaf-out dates of 1126 temperate woody species grown in eight Northern Hemisphere common gardens. For these species, information on the native climate and phylogenetic position was collected. Using linear regression analyses, we examine the relative effect of climate variables and phylogeny on leaf out variation among species.
\end{abstract}

Results: Climate variables explained twice as much variation in leaf out timing as phylogenetic information, a process that was driven primarily by the complex interactive effects of multiple climate variables. Although the primary climate factors explaining species-level variation in leaf-out timing varied drastically across different families, our analyses reveal that local adaptation plays a stronger role than common evolutionary history in determining tree phenology across the temperate biome.

Conclusions: In the long-term, the direct effects of physiological adaptation to abiotic effects of climate change on forest phenology are likely to outweigh the indirect effects mediated through changes in tree species composition.

Keywords: Leaf emergence, Temperate tree species, Phylogeny, Climate, Carbon cycling

\section{Background}

Temperate forest trees have a prominent influence on the global carbon cycle. Following leaf emergence in spring, increases in tree photosynthesis drive a considerable uptake of carbon from the atmosphere. Predicting the timing of leaf emergence is necessary if we are to effectively model global carbon dynamics throughout the year. A considerable body of research highlights the abiotic drivers of this phenomenon: leaf unfolding in many species is triggered by winter chilling, rising temperatures in spring,

\footnotetext{
* Correspondence: thomas.crowther11@gmail.com

${ }^{\dagger}$ Equal contributors

${ }^{1}$ Department of Terrestrial Ecology, Netherlands Institute of Ecology

(NIOO-KNAW), Droevendaalsesteeg 10, 6708, PB, Wageningen, The Netherlands

${ }^{3}$ Institute of Integrative Biology, ETH Zurich, Univeritätstrasse 16, Zurich,

Switzerland

Full list of author information is available at the end of the article
}

and, to a lesser degree, increasing day-length (Heide 1993a,b; Körner 2006; Ghelardini et al. 2010; Polgar and Primack 2011; Basler and Körner 2012; Laube et al. 2014; Polgar et al. 2014; Zohner et al. 2016). However, species vary with respect to the specific cues that trigger leaf emergence. Therefore, multiple species in the same location will leaf out at different times in the season, and changes in species distributions can drastically alter the timing of leaf emergence across the temperate biome. Understanding this variation necessitates a fundamental understanding of the evolutionary drivers of leaf emergence across temperate forests.

The timing of leaf emergence reflects a trade-off between the advantages of maximizing photosynthetic carbon uptake and the costs of frost damage (Kramer et al. 2010). That is why temperate tree species have developed precise 
physiological mechanisms (interactive effects of winter chilling, spring warming and day length) to control bud development (Linkosalo et al. 2006). The physiological mechanisms associated with leaf unfolding are genetically controlled and so these traits are maintained when trees are transplanted to new environments (Körner and Basler 2010; Ghelardini et al. 2014). The native climate of species has a strong influence on leaf-out strategy: species originating from higher latitudes will leaf out at an earlier time than contemporaries from lower latitudes when growing under identical conditions (Zohner and Renner 2014). Also, recent studies showed that a species' leaf-out phenology is to a certain degree determined by its phylogenetic position, with closely related species leafing out at more similar times than distantly related species (Panchen et al. 2014; Zohner et al. 2017). This might be the result of developmental or architectural constraints inherent in the phylogenetic history of a species (Lechowicz 1984). Yet the relative importance of local adaptation to climate and phylogenetic constraints remain untested in temperate trees. Disentangling these two poorly understood processes is critical to generating a mechanistic understanding of leaf emergence in temperate forests, particularly given their potentially contrasting implications for the response to climate change (Panchen et al. 2014).

The question about the relative importance of native environmental conditions or ancient evolutionary background in governing an organismal trait is a classic question in ecology. In essence, it is a question of whether it is the deep evolutionary history, or adaptation to environmental conditions that determines the leaf-out timing of any temperate tree species. Here, we used data on temperate trees from common gardens to explore the relative importance of climate conditions and evolutionary relatedness in governing the similarity of leaf out timing of 1192 tree species across the temperate biome. Using this common garden approach, we can ensure that all individuals are experiencing the same environmental conditions, so differences in leaf-out timing are driven by genetically determined behaviour as a result of adaptation to native climate conditions and/or evolutionary relatedness. We also explored the importance of relatedness across four different phylogenetic scales (species, genus, family and order) to examine the level at which relatedness has the strongest influence on leaf out timing. Finally, we revealed the contrasted effect of species' phylogenetic position and native abiotic conditions (various climate variables) on the timing of leaf emergence in different temperate woody families.

\section{Results}

Phylogenetic relatedness and climate variables contribute unequally to leaf out timing

Overall, phylogenetic relatedness explained a relatively small proportion of the variation in leaf out timing across our 1126 tree species, but the importance of relatedness varied across the phylogenetic levels. Relatedness at the genus and species levels explained between $2 \%$ and $3.4 \%$ of the variation in leaf out timing across the temperate woody species (Fig. 1a, Table 1). Order or family similarity explained little or no variation in leaf out timing. That is, species from the same genus or closely related genera are more likely to share similar leaf out dates when growing under common garden conditions, whereas no such assumption can be made for species that belong to closely related families or orders.

Despite the significant role of phylogenetic relatedness at the species and genus level, a full combination of climate variables explained a greater proportion of the variation in leaf out timing across species (Fig. 1b). Indeed, when phylogeny explains $2 \%$ of leaf-out timing, climate and interaction between phylogeny and climate explained $3 \%$ and $1 \%$ of leaf-out variability, respectively (Fig. 1b, Table 1). These results demonstrate the important role of adaptation to local environments. However, the influence of climate conditions in regulating leaf out timing was not simple; no single climate variable explained more than $36.4 \%$ of the variation in leaf out timing explained by climate. The most important climate variables were precipitation of coldest quarter (Bio19), annual mean temperature (Bio1), elevation and annual precipitation (Bio12). Overall the interactive effects of the different climate variables explained by far the largest proportion of the variation in leaf out timing across all temperate tree species where more than $75 \%$ of climate effect was triggered by climate interactions.

\section{Leaf-out timing in temperate tree families is modulated by contrasting climate variables}

To examine these interactive effects further, we examined the relative importance of climate and phylogeny for explaining the differences in leaf out timing for the species within each family. For the vast majority of families, climate variables were more important in explaining leaf out time (see low Phylogeny-Climate ratios; Figure 2). Although there were no clear trends regarding which climate variables best explained within-family variation in leaf-out timing across the different families, some strong and contrasted relationships emerged. For example, mean annual temperature (Bio1) and elevation explained up to $13 \%$ of the species-level variation in leaf-out timing within the Betulaceae family. Annual precipitation (Bio12) was a particularly strong determinant of leaf out timing within the Fagaceae family. Despite these trends, the role of phylogeny did outweigh climate in three families (Phylogeny/ Climate ratios $>1$, Figure 2): Leaf-out timing in the only two Conifer families present in this study (Pinaceae and Cupressaceae), as well as in the Oleaceae was better explained by 

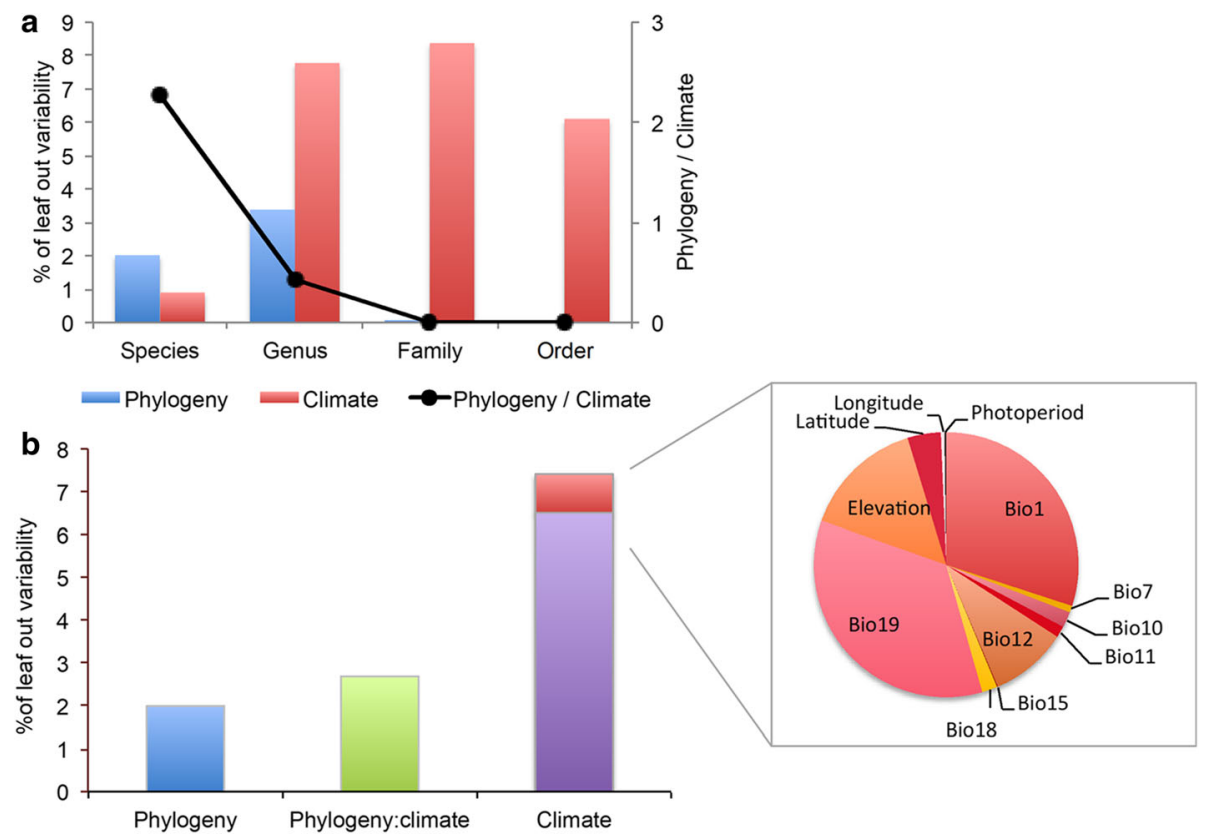

Fig. 1 Variables explaining leaf-out timing in temperate trees grown under common conditions. a Between-species leaf-out variability is explained by phylogeny (blue) and native climate (red) at different phylogenetic levels. Black dots and edges represent phylogeny to climate ratios on leaf-out variability across species, genus, family and order. $\mathbf{b}$ Leaf-out variability is explained by phylogeny (blue), interactions between phylogeny and climate variables (green), climate (red) and interactions between climate variables (purple) at species level. Box is a zoom of the relative proportion of leaf out variability explained by 11 climate variables

species relatedness, phylogeny explained $4.4 \%, 7.4 \%$ and $12 \%$ of the variation in leaf-out timing respectively.

\section{Discussion}

Our results reveal the importance of native environmental conditions and phylogenetic relatedness in determining leaf-out strategies in temperate woody species. Overall, we show the varying extent to which phylogeny and adaptation to local climates affect leaf-out variation at different phylogenetic levels. In essence, within families, the interaction between the different 'climate' variables better explained between-species variation in innate leaf-

Table 1 Percentages of the variation in leaf out timing explained by the different parameters included in the model for each phylogenetic level studied

\begin{tabular}{|c|c|c|c|c|}
\hline Parameter & Species & Genus & Family & Order \\
\hline Phylogeny & 2.00 & 3.39 & 0.01 & 0.03 \\
\hline Phylogeny:climate & 1.07 & - & - & - \\
\hline Climate:climate & 2.60 & - & - & - \\
\hline Bio1 (Annual Mean Temperature) & 0.27 & 1.13 & 3.21 & 0.43 \\
\hline Bio7 (Temperature Annual Range) & 0.01 & 0.09 & 0.10 & 0.31 \\
\hline Bio10 (Mean Temperature of Warmest Quarter) & 0.02 & 0.14 & 0.59 & 1.53 \\
\hline Bio11 (Mean Temperature of Coldest Quarter) & 0.01 & 0.09 & 0.38 & 0.29 \\
\hline Bio12 (Annual Precipitation) & 0.09 & 2.53 & 0.00 & 0.57 \\
\hline Bio15 (Precipitation Seasonality) & 0.00 & 0.10 & 0.90 & 1.00 \\
\hline Bio18 (Precipitation of Warmest Quarter) & 0.02 & 0.00 & 0.98 & 0.03 \\
\hline Bio19 (Precipitation of Coldest Quarter) & 0.31 & 0.69 & 0.08 & 0.00 \\
\hline Elevation & 0.13 & 1.18 & 0.62 & 0.35 \\
\hline Photoperiod & 0.00 & 0.00 & 0.00 & 0.00 \\
\hline Total & 6.53 & 9.34 & 6.89 & 4.56 \\
\hline
\end{tabular}


$25 \%$ Phylogeny/Climate

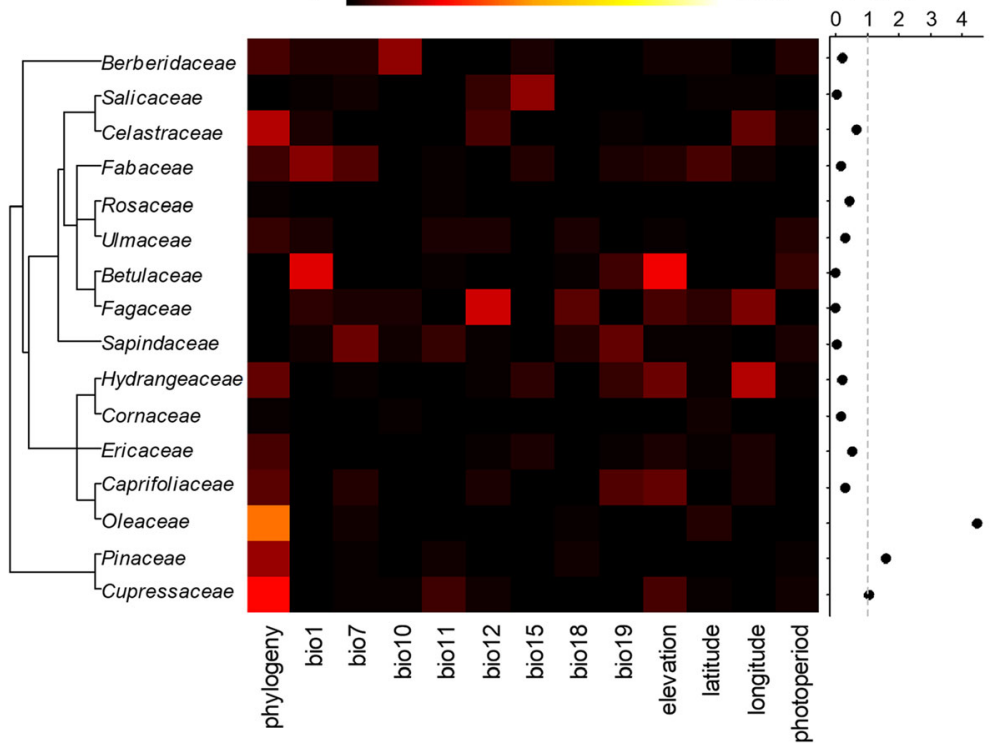

Fig. 2 Heatmap of leaf-out variability explained by phylogeny and 11 climate variables in the different families studied. Phylogeny to climate ratios are presented on the right panel for each family

out behaviour than 'phylogeny' across temperate ecosystems (Fig. 1b). The relative importance of phylogenetic relatedness increases towards lower taxonomic levels. Thus, two species from closely related genera or within the same genus are more likely to share similar leaf out dates when growing under common garden conditions (Fig. 1a). This underscores that the timing of leaf emergence underlies a balance between phylogenetic constraints and adaptation to specific environmental conditions that can be common between closely related species. As such, on an evolutionary timescale, the molecular mechanisms involved in the perception of temperature and photoperiod signals are readily fine-tuned in response to local environmental conditions (Zohner et al. 2017). Following this trend, the relative importance of phylogenetic similarity vs climate similarity increases as one moves from the order-level to the species-level. This finding corroborates the shared contribution of phylogenetic and spatial effects in shaping species' leaf-out strategy. Nevertheless, we provide here the first evidence for a fluctuating and contrasted importance of phylogeny vs climate adaptation in temperate tree signalling.

In the Pinaceae, Cupressacaeae (the two and only representatives of the conifers in our study) and Oleaceae, leaf out timing was better explained by species relatedness compared to local climate, indicating that species' leaf-out strategy within these families is conserved as a consequence of the constraints of past evolutionary history. Interestingly, both Pinaceae and Cupressaceae families include a large number of evergreen species (in this study, 67 out of 73 and 17 out of 20 in Pinaceae and
Cupressaceae, respectively) which are thought to be less sensitive to climatic conditions than deciduous species (Bai et al. 2015). In these evergreen species, leaves from past years can still photosynthesize during early spring. New leaves can therefore develop long after the risk of frost has passed and do not need fine-tuning of their physiological responses to environmental cues (Panchen et al. 2014).

The variability in the rates at which different tree families adapt to climate conditions suggests that some groups will be more strongly impacted by climate change than others. Slowly evolving woody species that are less adapted to local climate conditions may face the most damaging impacts of climate change, as they will be less capable of adapting to change. In addition, the environmental variables that best explained the variation in leaf out timing within different families varied dramatically, highlighting the taxon-specific ways that different tree species might respond to climate change. For example, although mean annual temperature has long been accepted as a prominent driver of the variation in leaf out timing, as observed here in many families, mean annual precipitation was by far the strongest predictor of leaf out timing within the Fagaceae family. This finding is in accordance with previous studies, which revealed strong correlations between rainfall and phenotypic traits such as tree growth and flowering in this family originating from the tropics (Reich and Borchert 1982; Volland-Voigt et al. 2011). Thus, in addition to temperature regimes, geographic differences in precipitation likely play an important role in driving genetically- 
determined variation in the timing of leaf-out among species.

Despite these individual effects of specific climate variables on the variability of leaf out timing within and across families, the interactive effects of different climate variables explained by far the greatest amount of variability across all tree species. These interactive climate effects are generally overlooked by most studies that search for specific environmental drivers of variation in plant phenology, but our study highlights the necessity to consider such interactions if we are to generate a predictive understanding of such variation. Indeed, biomes are controlled by a various array of climate variables, which will be differentially affected by global change. It is timely to use large phenotypic and climatic datasets to model the consequences of global change on essential biological processes.

\section{Conclusions}

Understanding the fundamental patterns in leaf out timing across temperate woody species is necessary to understand the temporal variations in the global carbon cycle within and across years. By combining phenotypic data from a vast range of species from different native climates and phylogenetic ranks, we can generate new insights into the consequences of ancient phylogenetic history and local climate adaptation on phenological traits at different taxonomic levels. Identifying which species are more likely to respond to changing environmental variables over the coming decades might help us to identify the species that will be more sensitive to fluctuating environmental conditions. This mechanistic understanding of how different temperate species might respond to changing environmental conditions can provide critical baseline information about changes in carbon dynamics under current and future climate scenarios.

\section{Methods}

\section{Study site, climate and phylogenetic datasets}

To gather information on the genetically-determined leafout variation between species, we used common garden leaf-out data for 1126 species observed in spring 2012 at eight Northern Hemisphere Gardens located in Eastern North America, Europe, and East Asia (see Panchen et al. 2014 and Fig. 3). Since we were not interested in phenotypic differences expressed as a result of climatic variation across gardens, for each species we calculated a single average leaf-out date, which was based on all available garden observations. To account for the fact that not all species were shared between sites we applied site-based corrections (= adjusted leaf-out date cf. Panchen et al. 2014). We therefore calculated a site-adjustment factor for each site as the difference between the mean leaf-out date at the respective site and the mean leaf-out date across all sites. Next, adjusted leaf-out dates were calculated by
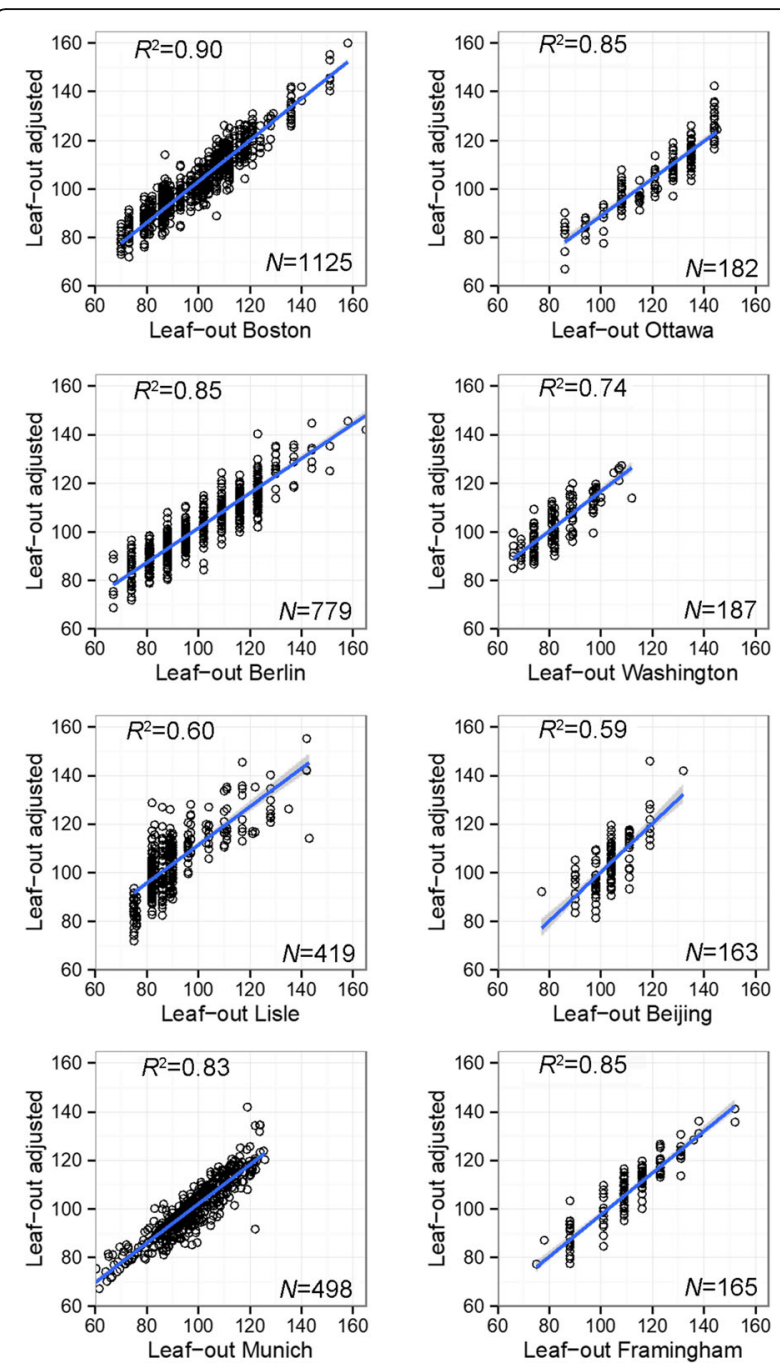

Fig. 3 Relationship between adjusted leaf-out dates averaged across sites and leaf-out dates monitored at each site. $R^{2}$ values of linear regressions are shown at the top of each panel, sample sizes are shown below. Beijing, Beijing Botanical Garden, China; Berlin, Botanic Garden and Botanical Museum Berlin-Dahlem, Germany; Boston, Arnold Arboretum, MA, USA; Framingham, Garden in the Woods, MA, USA; Lisle, Morton Arboretum, IL, USA; Munich, Munich Botanical Garden, Germany; Ottawa, Ottawa Arboretum, Canada; and Washington, US National Arboretum, DC and Beltsville, MD, USA. Data from Panchen et al. (2014)

adding the respective adjustment factor to a species' leafout date at each site. Finally, species-specific leaf-out dates were obtained by averaging the adjusted leaf-out dates across sites. Leaf-out dates of species averaged across sites well reflected species leaf-out dates at each site (mean $R^{2}=0.80$; see Fig. 3 in which leaf-out dates averaged across sites are regressed against observed leaf-out dates at each site).

Native climate was assigned as described in Zohner et al. (2017): Georeferenced occurrences (from the Global Biodiversity Information Facility; http://www.gbif.org/) of the species were queried against grid files (2.5-arc minute 
spatial resolution data) from the Worldclim dataset (Hijmans et al. 2004, 2005). In the present study, 10 climate variables were used, corresponding to: Annual Mean Temperature (Bio1), Temperature Annual Range (Bio7), Mean Temperature of Warmest Quarter (Bio10), Mean Temperature of Coldest Quarter (Bio11), Annual Precipitation (Bio12), Precipitation Seasonality (Coefficient of Variation; Bio15), Precipitation of Warmest Quarter (Bio18), Precipitation of Coldest Quarter (Bio19), Elevation and Photoperiod. For each species, we determined the optimum by calculating its 0.5 quantile (median) for the respective variable.A total of 1126 woody species from 42 orders was used in this study and is presented in Table 2.

The phylogeny (PHYLOMATIC tree) used in this study was available from Panchen et al. (2014) and we manually added missing species. Its topology reflects the APG III (2009) phylogeny, with a few changes based on the Angiosperm Phylogeny Website (http://www.mobot.org/MOBOT/research/APweb/welcome.html). Branch lengths reflect divergence time estimates based on the fossil record.

\section{Statistical analysis}

To highlight the effect of the different climate variables and phylogeny on leaf out variability, we performed a linear regression analyses. A separate analysis was performed at different taxonomic levels (species, genus, family and order) (Figure 1a). For each taxonomic level, the mean of climate variables for species, genus, family or order, accordingly, was used to build Euclidean distance matrices using the dist function in $\mathrm{R}$ ( $\mathrm{R}$ Core Team, 2013). The covariance matrix of phylogenetic data was obtained using the vcv.phylo function from the ape library in $\mathrm{R}$ (Paradis et al. 2004). The regression analysis was performed using the $\mathrm{lm}$ function in R. The linear model used was: leafout phylogeny + bio1 + bio7 + bio10 + bio11 + bio12 + bio15 + bio18 + bio19 + elevation + photoperiod. The percentage of leaf out variability explained by climate corresponds to the sum of percentage of leaf out variability explained by each climate variable.

To test the effects of interactions between variables, models with different complexity levels were tested at the species level. All combinations of variables, with and without interactions were tested. The Akaike Information Criterion (AIC) was then used to compare all the hypothetical models. The model selected (with lower AIC) was the most exhaustive model and includes phylogenetic relatedness, all climate variables and interactions between each variable.

In the same way, separate analyses were performed for each family with more than 20 species (Figure 2). The same model including phylogenetic relatedness and climate

Table 2 Number of species, genera and families for the 42 orders used in this study

\begin{tabular}{|c|c|c|c|c|c|c|c|}
\hline Order & Family & Genus & Species & Order & Family & Genus & Species \\
\hline Apiales & 1 & 5 & 8 & Leitneriales & 1 & 1 & 1 \\
\hline Aristolochiales & 1 & 1 & 2 & Liliales & 1 & 1 & 1 \\
\hline Celastrales & 2 & 4 & 38 & Magnoliales & 4 & 5 & 15 \\
\hline Cornales & 1 & 4 & 24 & Malvales & 3 & 7 & 15 \\
\hline Diapensiales & 1 & 1 & 1 & Myricales & 1 & 1 & 2 \\
\hline Dilleniales & 1 & 1 & 1 & Myrtales & 2 & 4 & 10 \\
\hline Dipsacales & 1 & 8 & 73 & Pinales & 4 & 21 & 93 \\
\hline Ebenales & 3 & 5 & 13 & Proteales & 1 & 3 & 7 \\
\hline Ephedrales & 1 & 1 & 2 & Ranunculales & 5 & 9 & 45 \\
\hline Ericales & 3 & 20 & 68 & Rhamnales & 2 & 7 & 20 \\
\hline Eucommiales & 1 & 1 & 1 & Rosales & 4 & 37 & 260 \\
\hline Euphorbiales & 2 & 3 & 5 & Rubiales & 1 & 4 & 4 \\
\hline Fabales & 1 & 22 & 42 & Salicales & 1 & 4 & 35 \\
\hline Fagales & 3 & 9 & 95 & Sapindales & 4 & 16 & 81 \\
\hline Gentianales & 1 & 1 & 1 & Saxifragales & 1 & 1 & 1 \\
\hline Ginkgoales & 1 & 1 & 1 & Scrophulariales & 3 & 13 & 52 \\
\hline Hamamelidales & 5 & 7 & 14 & Solanales & 1 & 1 & 2 \\
\hline Illiciales & 1 & 1 & 1 & Theales & 2 & 5 & 12 \\
\hline Juglandales & 1 & 5 & 20 & Trochodendrales & 1 & 1 & 1 \\
\hline Lamiales & 2 & 4 & 10 & Urticales & 4 & 11 & 32 \\
\hline Laurales & 2 & 5 & 9 & Violales & 5 & 5 & 8 \\
\hline
\end{tabular}


variables without interaction was used. The percentage of leaf out explained by each variable is represented by a heatmap created using the function heatmap in R. Plots of the comparative ratios between phylogeny and climate contributions correspond to explained variability of phylogeny divided by the sum of leaf out variability explained by all climatic variables.

\section{Abbreviations}

AIC: Akaike Information Criterion

\section{Funding}

This work was supported by a personal Marie Curie grant to T.W.C.

\section{Authors' contributions}

The conceptual framework for the analyses was developed by J.F.C and T.W.C. C.M.Z. provided the datasets and contributed to the interpretation of the results. E.D. analysed the data. E.D., J.F.C. and T.W.C wrote the manuscript. All authors read and approved the final manuscript.

\section{Ethics approval and consent to participate}

Not applicable.

\section{Consent for publication}

Not applicable.

\section{Competing interests}

The authors declare no competing financial interest.

\section{Author details}

'Department of Terrestrial Ecology, Netherlands Institute of Ecology (NIOO-KNAW), Droevendaalsesteeg 10, 6708, PB, Wageningen, The Netherlands. ${ }^{2}$ Systematic Botany and Mycology, Department of Biology, University of Munich (LMU), 80638 Munich, Germany. Institute of Integrative Biology, ETH Zurich, Univeritätstrasse 16, Zurich, Switzerland.

Received: 8 August 2017 Accepted: 21 October 2017

Published online: 12 December 2017

\section{References}

APG III (2009) An update of the angiosperm phylogeny group classification for the orders and families of flowering plants: APG III. Bot J Linn Soc 161(2): $105-121$

Bai K, He C, Wan X, Jiang D (2015) Leaf economics of evergreen and deciduous tree species along an elevational gradient in a subtropical mountain. AoB Plants. doi:10.1093/aobpla/plv064

Basler D, Körner C (2012) Photoperiod sensitivity of bud burst in 14 temperate forest tree species. Agric For Meteorol 165:73-81

Ghelardini L, Santini A, Black-Samuelsson S, Myking T, Falusi M (2010) Bud dormancy release in elm (Ulmus spp.) clones - a case study of photoperiod and temperature responses. Tree Physiol 30(2):264-274. doi:10.1093/treephys/ tpp110

Ghelardini L, Berlin S, Weih M, Lagercrantz U, Gyllenstrand N, Rönnberg-Wästljung AC (2014) Genetic architecture of spring and autumn phenology in Salix. BMC Plant Biol 14:31

Heide OM (1993a) Daylength and thermal time responses of budburst during dormancy release in some northern deciduous trees. Physiol Plant 88(4):531-540. doi:10.1111/.1399-3054.1993.tb01368.x

Heide OM (1993b) Dormancy release in beech buds (Fagus sylvatica) requires both chilling and long days. Physiol Plant 89(1):187-191. doi:10.1111/j.13993054.1993.tb01804.x

Hijmans RJ, Cameron SE, Parra JL, Jones PG, Jarvis A (2004) The WorldClim interpolated global terrestrial climate surfaces. Version 1.3. http://datadryad. org/handle/10255/dryad.12700. Accessed 21 Apr 2011

Hijmans RJ, Cameron SE, Parra JL, Jones PG, Jarvis A (2005) Very high resolution interpolated climate surfaces for global land areas. Int J Climatol 25(15):1965-1978

Körner C (2006) Plant $\mathrm{CO}_{2}$ responses: an issue of definition, time and resource supply. New Phytol 172(3):393-411. doi:10.1111/j.1469-8137.2006.01886.x
Körner C, Basler D (2010) Phenology under global warming. Science 327:1461-1462. doi:10.1126/science.1186473

Kramer K, Degen B, Buschbom J, Hickler T, Thuiller W, Sykes MT, de Winter W (2010) Modelling exploration of the future of European beech (Fagus sylvatica $\mathrm{L}$.) under climate change-Range, abundance, genetic diversity and adaptive response. For Ecol Manag 259(11):2213-2222. doi:10.1016/j.foreco.2009.12.023

Laube J, Sparks TH, Estrella N, Menzel A (2014) Does humidity trigger tree phenology? Proposal for an air humidity based framework for bud development in spring. New Phytol 202(2):350-355. doi:10.1111/nph.12680

Lechowicz MJ (1984) Why do temperate deciduous trees leaf out at different times? Adaptation and ecology of forest communities. Am Nat 124(6):821-842

Linkosalo T, Häkkinen R, Hänninen H (2006) Models of the spring phenology of boreal and temperate trees: Is there something missing? Tree Physiol 26(9): $1165-1172$

Panchen ZA, Primack RB, Nordt B, Ellwood ER, Stevens AD, Renner SS, Willis CG, Fahey R, Whittemore A, Du Y, Davis CC (2014) Leaf out times of temperate woody plants are related to phylogeny, deciduousness, growth habit and wood anatomy. New Phytol 203(4):1208-1219. doi:10.1111/nph.12892

Paradis E, Claude J, Strimmer K (2004) APE: analyses of phylogenetics and evolution in R language. Bioinformatics 20(2):289-290. doi:10.1093/ bioinformatics/btg412

Polgar C, Gallinat A, Primack RB (2014) Drivers of leaf-out phenology and their implications for species invasions: insights from Thoreau's Concord. New Phytol 202(1):106-115. doi:10.1111/nph.12647

Polgar CA, Primack RB (2011) Leaf-out phenology of temperate woody plants: from trees to ecosystems. New Phytol 191(4):926-941. doi:10.1111/j.14698137.2011.03803.x

R Core Team (2013) R: A language and environment for statistical computing. $R$ Foundation for Statistical Computing, Vienna

Reich PB, Borchert R (1982) Phenology and ecophysiology of the tropical tree, Tabebuia neochrysantha (Bignoniaceae). Ecology 63(3):294-299. doi:10.2307/ 1938945

Volland-Voigt F, Bräuning A, Ganzhi O, Peters T, Maza H (2011) Radial stem variations of Tabebuia chrysantha (Bignoniaceae) in different tropical forest ecosystems of southern Ecuador. Trees 25(1):39-48. doi:10.1007/s00468-0100461-6

Zohner CM, Benito BM, Svenning JC, Renner SS (2016) Day length unlikely to constrain climate-driven shifts in leaf-out times of northern woody plants. Nat Clim Chang 6(12):1120-1123. doi:10.1038/nclimate3138

Zohner CM, Renner SS (2014) Common garden comparison of the leaf-out phenology of woody species from different native climates, combined with herbarium records, forecasts long-term change. Ecol Lett 17(8):1016-1025. doi:10.1111/ele.12308

Zohner CM, Benito BM, Fridley JD, Svenning JC, Renner SS (2017) Spring predictability explains different leaf-out strategies in the Northern Hemisphere woody floras. Ecol Lett 20(4):452-460

\section{Submit your manuscript to a SpringerOpen ${ }^{\circ}$ journal and benefit from:}

- Convenient online submission

- Rigorous peer review

- Open access: articles freely available online

- High visibility within the field

- Retaining the copyright to your article

Submit your next manuscript at $>$ springeropen.com 